\title{
Trend analysis of sediment flux time series from tropical river basins in India using non-parametric tests and multiscale decomposition
}

\author{
S. Adarsh ${ }^{1} \cdot$ M. S. VishnuPriya ${ }^{1} \cdot$ Sajan Narayanan $^{1} \cdot$ M. S. Smruthi ${ }^{1}$ • \\ Paul George $^{1} \cdot$ Nikitha Miriam Benjie $^{1}$
}

Received: 15 October 2016/ Accepted: 19 October 2016/Published online: 28 October 2016

(C) Springer International Publishing Switzerland 2016

\begin{abstract}
This paper first analyzed the trend of annual sediment flux time series from seven major basin outlet stations in India using the non-parametric Mann-Kendall (MK) method. Then the non-linear trends in these series were extracted using the empirical mode decomposition (EMD) method. Similar procedure is followed upon annual rainfall of the basin and a comparison of trend is made with that of sediment load. Results of trend analysis study showed a reduction in sediment flux in five out of seven tropical river basins in India despite the increase in rainfall in three among them. Despite the significant reduction in rainfall, the sediment flux from Chennur station in Pennar basin showed an increasing trend, which is attributed to large flow diversion in the upper reaches of the station. The application of continuous wavelet transform (CWT) analysis confirmed that anthropogenic impact is the major driver behind the sediment flux variability of tropical river basins in India. Then for a microscopic examination of trend in monthly sediment flux data from different stations, first the change points in them were identified by the Hubert's segmentation procedure. For each of the identified segments, the trend is examined using the MK test and EMD method. The nature of trend captured by both methods is similar for most of the cases with discrepancies for few cases. The discrete wavelet transform (DWT) analysis is applied for such segments with discrepancies following extensive sensitivity analysis on mother wavelet type and decomposition levels. The similar nature of trend by DWT as that of EMD confirmed that EMD method is
\end{abstract}

S. Adarsh

adarsh.sankaran@yahoo.in

1 Department of Civil Engineering, TKM College of Engineering, Kollam, Kerala 691005, India successful in capturing the 'true' inherent non-linear trend in sediment flux series.

Keywords Sediment - Trend - MK test - EMD - Wavelet transform

\section{Introduction}

The summer monsoon rainfall during June-September, which is nearly $80 \%$ of the annual rainfall, predominantly influences the streamflow, sediment transport and channel morphology of the tropical Indian rivers (Kale 2002). The rain and flowing water lead to the erosion of fertile topsoil in large quantities and are carried to the sea/ocean. Large scale landslides and earthquakes as well as human activities such as deforestation, mining, and construction works, accelerate this process. Knowledge of the sediment flux carried by streams is necessary for the estimation of life of storage reservoirs, functioning and operation of hydraulic structures etc. In the recent years a significant reduction in the sediment flux carried by the tropical Indian rivers and which may have serious implications on hydrology of these basins and economically vital and also densely populated coastal zones of India (Panda et al. 2011). This is primarily due to the anthropogenic entrapments in reservoirs, which has resulted in noticeable changes in the hydrological, geomorphological, ecological functioning of the river basins (Walling and Fang 2003; Chakrapani 2005; Syvitski et al. 2005). Changes in sediment yield reflect changes in basin conditions including climate, soil erosion rate, vegetation, topography and land use. Fluctuations in sediment flux affect many terrestrial and coastal processes including ecosystem responses, because many nutrients and chemicals are also transported along with the sediment load. 
There is a significant difference between the Gangetic river system and the tropical (Peninsular) river system in the wealth of sediment load (as the former carries annual average sediment of $2390 \mathrm{t} / \mathrm{km}^{2}$ from the highly erodible Himalayan range while latter carries nearly $216 \mathrm{t} / \mathrm{km}^{2}$ (Milliman and Meade 1983). The Gangetic river system experiences a perennial flow regime due to the melting of the glaciers of the Himalayan mountains during the nonmonsoon period while the seasonality of flow in the tropical rivers has led to the construction of multi-purpose dams and reservoirs (Agrawal and Chak 1991) in order to safeguard the flood prone deltaic region and also to supply water during the drought and non-monsoon period. Most of the tropical Indian basins suffered serious reduction in its sediment wealth and lead to many environmental problems in the past. For example, Malini and Rao (2004) observed that the landward progression of the Godavari River basin led to evacuation of coastal establishments and loss of mangrove forest and they attributed this coastal erosion to the drastic reduction in sediment supply due the upstream reservoir constructions. Bobba (2002) reported the cases of seawater intrusion into the coastal aquifer of the basin. It was reported that the Krishna River basin- the largest regulated river basin in term of dams and reservoirs in India- experienced coastal erosion due to the drastic reduction in streamflow and sediment flux (Bouwer et al. 2006; Biggs et al. 2007; Gamage and Smakhtin 2009). Gupta and Chakrapani (2005) reported that the upstream damming in the Narmada River basin has resulted in significant reduction in sediment flux to the Arabian Sea. Syvitski et al. (2009) noted that the Mahanadi-Brahmani and Godavari basins were at greater risk to coastal erosion.

Trend identification is a required task in hydrological series analysis, because it is the basis not only for understanding the long-term variations of hydrological processes, but also for revealing periodicities and other characteristics of hydrological processes. Infact while analyzing the changes in sediment flux series attempts should be made to understand whether the exact reason behind increasing and decreasing sediment flux is due to anthropogenic causes or changes in climatic systems accordingly the studies should be delineated (Syvitski 2003). Zhang et al. (2008) applied continuous wavelet transform (CWT) for analyzing the trend and periodicity estimation of sediment load and runoff from different stations in the Yangtze river basin in China. A major obstacle to assess the impacts of climate and anthropogenic activity on the global sediment system is the lack of reliable sediment monitoring (Dearing and Jones 2003). In India, the sediment monitoring program with adequate spatial representation of the river basins commenced in the mid-1980s. However, some of the tropical rivers have relatively long time series for a few stations at the mouth of the river, and have also been used for the trend analysis (e.g. Malini and Rao 2004; Gamage and Smakhtin 2009).

However, trend identification is a difficult problem in practice because of the diverse performances of those methods used for trend analysis (see Sonali and Nagesh Kumar 2013). Two problems should be answered in trend estimation of time series: evaluation of the magnitude and statistical significance of trend, and determination of the specific shape of trend. The magnitude and nature of the trend can be identified using the popular non-parametric methods such as Mann-Kendall method and Sen's slope estimator while the specific shape of trend cannot be captured by such methods. Also it is reported that most of the hydroclimatic series may possess inherent non-linear trend rather than the traditional notion of linear trend $(\mathrm{Wu}$ et al. 2007; Sang et al. 2014; Franske 2014; Unnikrishnan and Jothiprakash 2015). Hence identification of inherent nonlinear trend is also equally important for proper modeling of hydrologic variables.

The specific objectives of the study include: (1) estimating the trend and its sequential change in sediment flux series from outlet stations of seven river basins in India; (2) evaluating the non-linear trend in annual sediment flux and rainfall time series of the seven stations using EMD; (3) perform a microscopic evaluation of trend of monthly sediment flux time series from the stations by segmentation operation.

\section{Materials and methods}

This section presents different methods used for this study.

\section{Modified Mann-Kendall (MMK) test}

The Mann-Kendall (MK) trend test (Mann 1945; Kendall 1975 ) is probably the most widely used non-parametric test to detect the nature as well as the statistical significance of the trend in hydro-meteorological variables. But a noticeable weakness of the MK test is that it does not account for serial correlation. It may lead to inaccurate interpretations of the MK test, as a time series exhibiting positive autocorrelation causes the effective sample size to be less than the actual sample size, thereby increasing the variance and the possibility of detecting significant trends when in fact, there are no trends (Hamed and Rao 1998; Ehsanzadeh et al. 2011). On contrary, the existence of negative autocorrelation in a time series enhances the possibility of accepting the null hypothesis (absence of significant trends), when actually, there are significant trends (Ehsanzadeh et al. 2011). To take care of this issue Hamed and Rao (1998) proposed a modified approach, in which the calculation of the variance of the test statistics $S$ is altered 
as given by an empirical formula. The rank correlation test for two sets of observations $X=x_{1}, x_{2}, \ldots, x_{n}$ and $Y=$ $y_{1}, y_{2}, \ldots, y_{n}$ is used in the modified MK test as follows:

The test statistic $S$ is calculated as

$S=\sum_{i<j} a_{i j} b_{i j}$

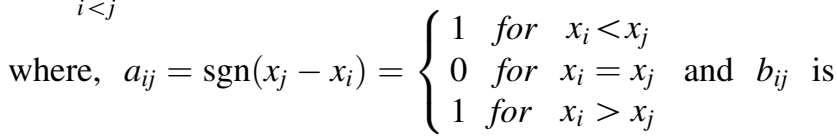

similarly defined for the observations in $Y$. The significance of trends is tested b y comparing the standardized test statistic $Z=S / \sqrt{\operatorname{Var}(S)}$ with the standard normal variate $Z$ at the desired significance level.

The variance of the test statistic can be computed as

$\operatorname{Var}(S)=\frac{n(n-1)(2 n+5)}{18}\left(\frac{n}{n^{*}}\right)$,

where $n$ is the actual number of observations and $n^{*}$ is the effective number of sample size needed in order to account for the autocorrelation factor in the dataset. The ratio $\left(n / n^{*}\right)$ is the factor that represents the correction associated with the autocorrelation of the data. Empirically, the correction is expressed by Hamed and Rao (1998) as follows:

$$
\begin{aligned}
\left(\frac{n}{n^{*}}\right)=1 & +\frac{2}{n(n-1)(n-2)} \\
& \sum_{i=1}^{n=1}(n-i)(n-i-1)(n-i-2) \rho(i),
\end{aligned}
$$

where $\rho(i)$ is the autocorrelation function of the ranks of the observations.

The test result, which is the standardized test statistic $Z$, gives not only the information about stationarity or nonstationarity but also whether the trend is upward or downward. If the computed value of $|Z|>Z_{\alpha / 2}$, then the null hypothesis of no trend is rejected at $\alpha$ level of significance in a two-sided test (i.e., the trend is significant). A positive value of $Z$ indicates an increasing trend and a negative value of $Z$ indicates a decreasing trend.

\section{Empirical mode decomposition (EMD)}

Empirical mode decomposition (EMD) is a signal decomposition method proposed by Huang et al. (1998), which decomposes a time series signal into different oscillatory modes having specific periodicity in purely empirical and data adaptive manner.

The different steps involved in the process are:

1. Identify all extrema (maxima and minima) of the signal $X(t)$.

2. Connect these maxima with any interpolation function (for example, cubic spline) to construct an upper envelope $\left(\mathrm{E}_{\max }(t)\right)$; use the same procedure for minima to construct a lower envelope $\left(\mathrm{E}_{\min }(t)\right)$.

3. Compute the mean of the upper and lower envelope, $m(t)$.

4. Calculate the difference time series $d(t)=X(t)-m(t)$.

5. Let $d(t)$ be the new signal and repeat steps (1) to (4) until $d(t)$ becomes a zero-mean series with no riding waves (i.e., there are no negative local maxima and positive local minima) with smoothened amplitudes. Such an oscillatory signal is called an Intrinsic Mode Function (IMF). To satisfy this step, an appropriate criterion is to be applied to stop the sifting iterations in order to guarantee that the IMF retains enough physical sense of both amplitude and frequency modulations (Huang and Wu 2008). A number of stopping criteria have been reported in the literature and the popular modified Cauchy type stopping criterion framed based on the deviation of the original time series from the mean in two consecutive sifting results (Huang and $\mathrm{Wu}$ 2008).

6. On satisfying the zero-mean condition, $d(t)$ can be designated as the first intrinsic mode function IMF1.

7. Compute the residue $R_{l}(t)$ by subtracting IMF1 from original signal (i.e., $R l(t)=X(t)-I M F l(t)$ is used as new signal. The 'sifting' process is repeated upon this signal to get IMF2.

8. The higher oscillatory modes are obtained by treating the residue $\left(R_{k}(t)\right)$ as the signal $(X(t))$, iteratively.

The $k$ th residue is defined as

$R_{k}(t)=X(t)-\sum_{j=1}^{k} I M F_{j}(t)$.

The process will be continued till the resulting residue is a monotonic function or a function having only one extrema. The above process of extracting the IMFs from a time series $X(t)$ is called as 'sifting' process. The final component is called 'residue', which indicates the long term inherent trend within the time series.

Then the original signal can be reconstructed as

$X(t)=\sum_{k=1}^{K}\left[I M F_{k}(t)\right]+R_{K}(t)$.

where, $K$ is the number of decomposed IMFs.

\section{Hubert's segmentation}

Hubert's segmentation procedure detects the multiple shifts in time series. The principle is to cut the series into $m$ segments $(m>1)$ such that the calculated means of the neighboring sub-series significantly differ. To limit the segmentation, the means of two contiguous segments must 
be different to the point of satisfying Scheffe's test (Scheffe 1959). The procedure gives the timing of the shifts. Giving a $m$ th order segmentation of the time series, $i_{k}$, $k=1, m$, the rank in the initial series of extreme end of the $k$ th segment (with $\mathrm{i}_{0}=0$ ), the following are defined by:

$\overline{x_{k}}=\frac{\sum_{i=i_{k-1}+1}^{i=i_{k}} x_{i}}{\left(i_{k}-i_{k-1}\right)}$,

$D_{m}=\sum_{k=1}^{k=m} \sum_{i=i_{k-1}+1}^{i=i_{k}}\left(x_{i}-\overline{x_{k}}\right)^{2}$.

$D_{m}$ is the quadratic deviation between the series and the segmentation. For a given segmentation order, the algorithm determine the optimal segmentation of a series that is such that the deviation $D_{m}$ is minimal. This procedure can also be interpreted as a stationary test, the null hypothesis being the studied series is non-stationary. If the procedure doesn't produce acceptable segmentations of order bigger or equal to two, the null hypothesis is accepted.

\section{Study areas and database}

The state and central government conducts hydrological observations at various river basins in India and the details are published in the website of Water resources Information System (WRIS) of India. The datasets of the sediment loads employed in this study are obtained from the WRIS India (http://india-wris.nrsc.gov.in/wris.html). The details of station and sediment data used for the study are given in Table 1. The suspended sediment data collected from 7 gauging stations located at the outlet of different basins namely Godavari, Krishna, Mahanadi, Cauvery, Pennar, Narmada and Tapi and the location map of different tropical basins in India as per WRIS classification is provided in Fig. 1. To examine the link between sediment flux and rainfall, the annual rainfall data for these river basins is used and which is taken from published literature (Ranade et al. 2007). The annual sediment data of the gauging stations of each river basin was selected corresponding to the time period for which rainfall data is available.

Table 1 River basins, outlet stations and period of data used for annual data analysis

\begin{tabular}{lclll}
\hline Sl. no. & Basin no. & River basin & Station & Time period \\
\hline 1 & 3 & Godavari & Polavaram & $06 / 1969-05 / 2005$ \\
2 & 4 & Krishna & Vijayawada & $02 / 1965-12 / 2005$ \\
3 & 8 & Mahanadi & Tikarapara & $06 / 1973-12 / 2005$ \\
4 & 5 & Cauvery & Mausiri & $04 / 1973-09 / 2005$ \\
5 & 9 & Pennar & Chennur & $09 / 1989-05 / 2005$ \\
6 & 12 & Narmada & Garudeshwar & $06 / 1987-12 / 2005$ \\
7 & 13 & Tapi & Sarankheda & $06 / 1984-05 / 2005$ \\
\hline
\end{tabular}

\section{Results and discussion}

The results of different analyses performed in the study along with proper discussion are provided in the following subsections.

\section{Trend analysis of annual sediment flux series}

In this study, first the trend in annual sediment flux and rainfall data for seven stations is estimated using MMK method. The results are given in Table 2 .

Based on the analysis it is noticed that the sediment flux from stations Polavaram, Tikarapara, Gurdudeswar, Vijayawada, Mausiri shows a significant reduction. The sediment flux time series off Chennur and Sarangkheda stations show increasing trend, even though the trend is not significant at $5 \%$ significance level. On estimating the trend in rainfall series, it is noticed that the trend is not significant in any of the stations. At Vijayawada, Tikarapara and Chennur stations, the trend in sediment flux and rainfall are opposing character. The similar nature of trend infer a broad inference on the influence of climatic variables (like rainfall) on sediment flux variability while opposing nature infer anthropogenic impact. The Mann-Kendall test helps to find magnitude, nature and statistical significance of trend of a time series. However, in hydrologic or climatic time series data, the identification of starting time period of the significant trends is also of great interest. Also the determination of changes of trend over time is important in any trend detection study. Sequential Mann-Kendall (SQMK) test is particularly useful for such change detection analysis and theoretical details of this test are provided in Appendix 1. The SQMK test is applied upon the monthly sediment flux series and the results are depicted as SQMK plots in Fig. 2.

The SQMK test identified the variation in trend of monthly sediment flux over the time domain under consideration. In the series from Polavaram station, a trend turning point is identified in $\sim 1993-94$ and over the majority of periods, the trend showed a mixed response (positive and negative) even though the trend was not significant. In the series from Vijayawada station, a trend turning point is noticed in $\sim 1968-69$ period; the trend showed an increasing nature for the decade 1990-2000 and the trend showed a consistent reduction since 2000s. A potential trend turning point is noticed in sediment flux series of Tikarapara station in 1993-94, after which the sediment flux showed a statistically significant increase. There is a reduction in sediment flux of Mausiri station after 1976-78 period, even though the reduction displayed statistical significance for shorter time spells. Sediment flux 
Fig. 1 River basins in India as per WRIS India classification (http://india-wris.nrsc.gov.in/ wris.html)

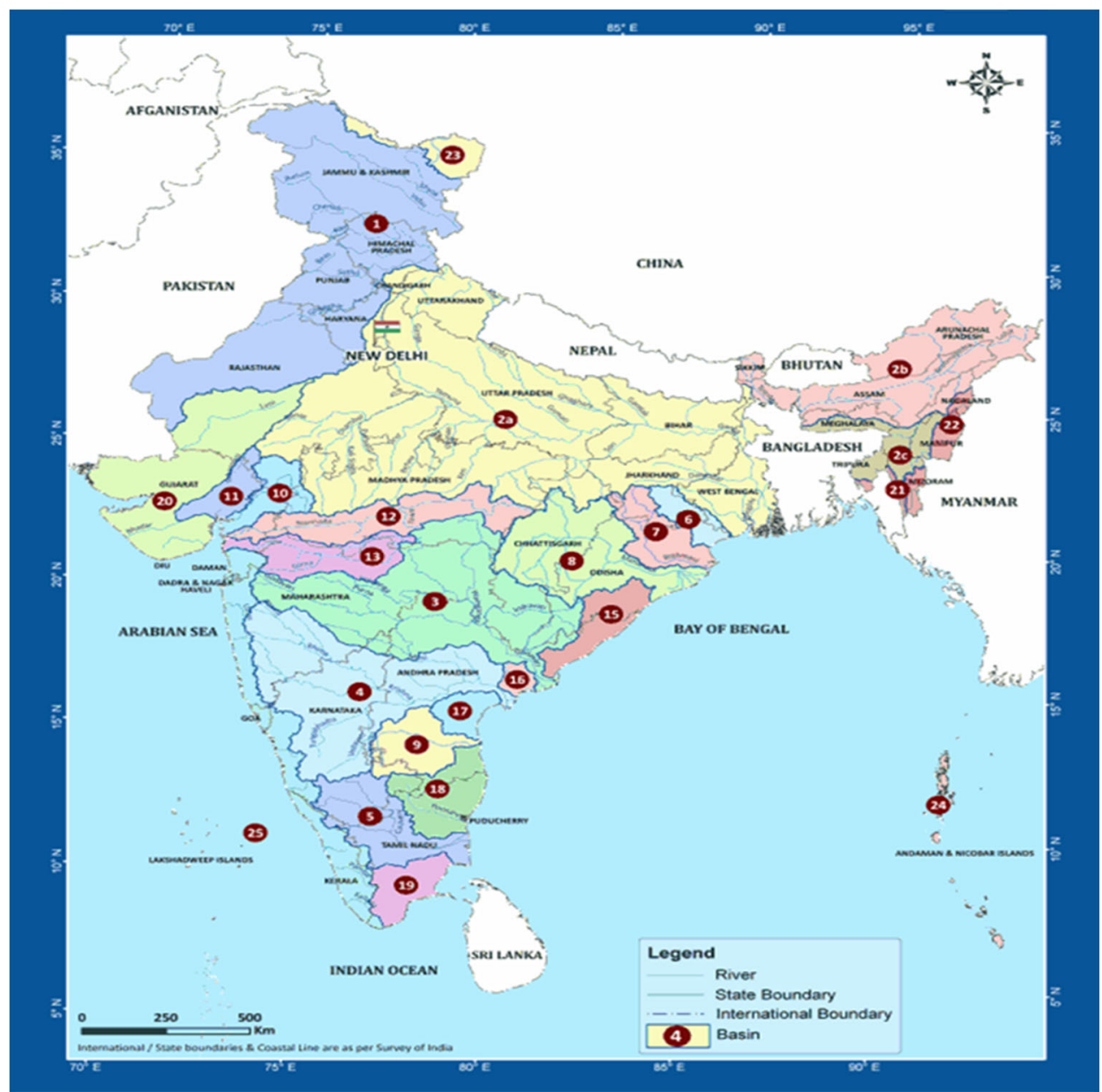

Table 2 Results obtained from MK method for annual sediment flux of various stations

\begin{tabular}{lcc}
\hline Station & \multicolumn{2}{l}{ Mann-Kendall } \\
\cline { 2 - 3 } & Sediment & Rainfall \\
\hline Polavaram & $\mathbf{- 2 . 7 0 7}$ & -0.17 \\
Vijayawada & $\mathbf{- 3 . 7 6 3}$ & 0.236 \\
Tikarapara & $\mathbf{- 3 . 3 9 1}$ & 1.1 \\
Mausiri & $\mathbf{- 2 . 8 0 4}$ & -0.108 \\
Chennur & 0.783 & -1.936 \\
Garudeshwar & $\mathbf{2 . 5 8 9}$ & 0.699 \\
Sarangkheda & 0.124 & 0.669 \\
\hline
\end{tabular}

The bold figures represents that the trend is significant at $5 \%$ significance level

from Chennur and Sarankheda stations showed more erratic behavior and not significant for majority of time spells and the latest trend turning points are noticed fairly within the duration $\sim 1996-1998$ in both these stations. There is a consistent reduction in sediment flux of Garudeshwar station since $1987(\sim)$ and reduction is significant reduction since 1993.
The MK test identifies the change in a non-parametric framework based on the pair-wise comparison of magnitude of the variable of interest. To portray the changes, the simple linear or non-linear trend analysis methods will be helpful. The linear trend in sediment flux and rainfall time series from different stations are fitted and non-linear trend in them are captured by the EMD method. The results of linear trend analysis and EMD based trend analysis are depicted in Fig. 3 and the observations made on the trend of sediment load and rainfall time series based on Fig. 3 are provided in the following paragraphs.

The linear trend plotted for Polavaram station shows an increasing trend for rainfall whereas decreasing trends for sediment flux. Similar kind of trend is shown by of annual sediment flux and annual rainfall data when EMD method is used. From Table 2 we can observe a significant decrease in sediment flux and a non-significant increase in rainfall trend using MK method. The floods in the central India, which supply large proportion of the sediment loads in the Godavari river basin, are primarily associated with the cyclonic storms and depressions developed over the Bay of Bengal during the monsoon season. The rise in sea 
(a) Polavaram

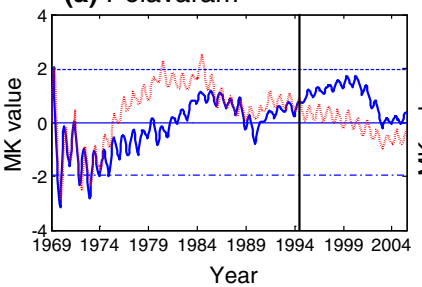

(e) Chennur

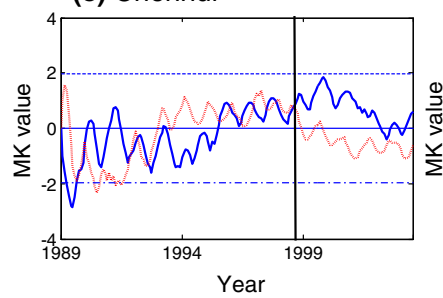

(b) Vijayawada

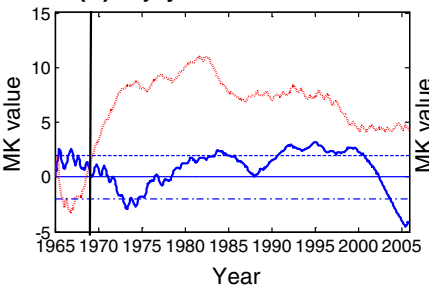

(f) Gurudeshwar

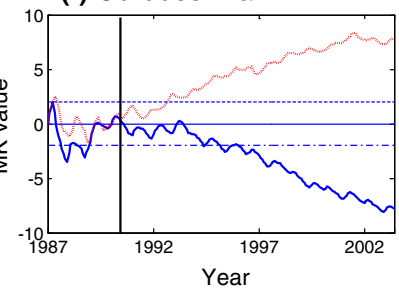

(c) Tikarapara

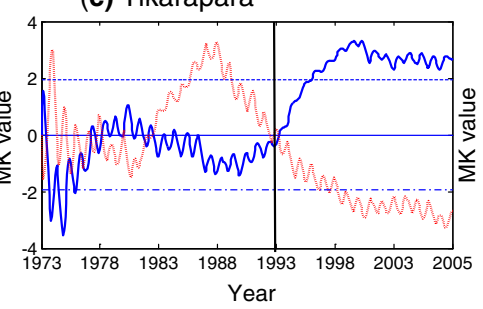

(f) Sarangkheda

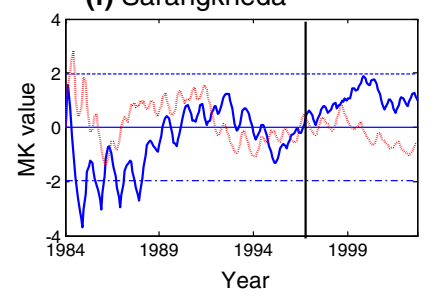

(d) Mausiri

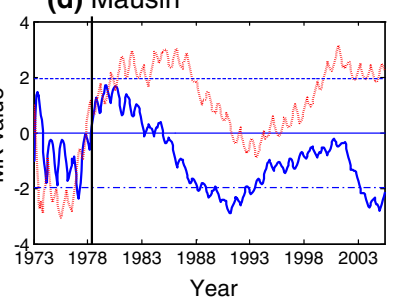

Fig. 2 SQMK test of monthly sediment flux series from different stations. The vertical bar indicate the trend turning point occurred

surface temperature has led to the intensification of the severe cyclonic storms in the non-monsoon seasons. The sediments are not only trapped in big reservoirs but also in the soil and water conservation measures which are adopted to meet the challenges of the frequent droughts. There are about 500 reservoir structures in this basin. Linear trend of sediment flux from Vijayawada shows a decreasing trend and that of rainfall data shows an increasing trend. EMD shows similar trends for sediment flux and annual rainfall data. From Table 2 we can observe significant decrease in sediment flux and non-significant increase in rainfall using MK method. The 473 dams which are present in the basin reduced the amount of sediment flux. A small deficit in rainfall triggers the anthropogenic intervention in terms of the rainfall conservation and storage of runoff in the reservoirs in order to meet the amplified water demands in drought years. As a result, the sediment supply has reduced substantially which can be attributed to the diversion of the streamflow.

The linear trendline plotted for Tikarapara station shows an increasing trend for rainfall and a decreasing trend for sediment flux. Similar nature of trend is noticed for the EMD based trends of annual sediment flux and annual rainfall data. From Table 2 we can observe a significant decrease in sediment flux and a non-significant increase in rainfall trend using MK method. Due to the diversion of the streamflow, the sediment supply has reduced substantially. The observed declination in sediment loads reflect the impacts of the frequent dry and deficit rainfall years and their interaction with the anthropogenic activities during the study period. The floods in the central India which supply large proportion of the sediment loads in the Mahanadi river basin are primarily associated with the cyclonic storms and depressions developed over the Bay of
Bengal during the monsoon season. The rise in sea surface temperature has led to the intensification of the severe cyclonic storms in the non-monsoon seasons. The anthropogenic control on the fluvial flux is primarily associated with the climatic stresses. The sediments are not only trapped in big reservoirs (the total number being 198) but also the soil and water conservation measures are intensified to meet the challenges of the frequent drought. Figure 3 shows the trends obtained for sediment flux and basin rainfall of Mausiri station. Linear trend of sediment flux shows a decreasing trend and that of rainfall data shows an increasing trend. EMD results show similar trends for annual sediment flux and annual rainfall data. From Table 2 we can observe a significant decrease in sediment flux and a non-significant increase in rainfall trend using MK method. The decrease in sediment flux despite the increase in rainfall can be attributed to the anthropogenic effect. There about 39 hydrologic structures in this basin. The sediment supply has reduced substantially which can also be attributed to the diversion of the streamflow. Therefore, the observed reduction in sediment loads reflect the impacts of the frequent dry and deficit rainfall years and their interaction with the anthropogenic activities during the study period. A small deficit or skewed distribution in rainfall triggers the anthropogenic intervention in terms of the rainfall conservation and storage of runoff in the reservoirs in order to meet the amplified water demands like irrigation, drinking water and industrial water requirements in a drought year.

At Chennur station, it is noticed that linear trend of sediment flux shows an increasing trend while that of rainfall data shows a decreasing trend. EMD based nonlinear trend shows similar nature for sediment flux and rainfall data. From Table 2 we can observe a non 
(a) Polavaram

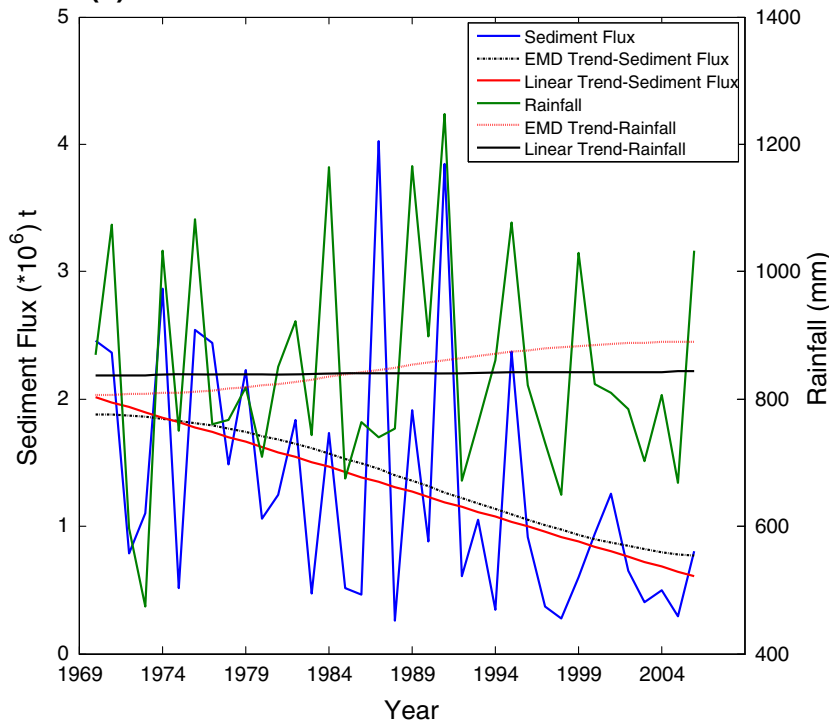

(c) Tikarapara

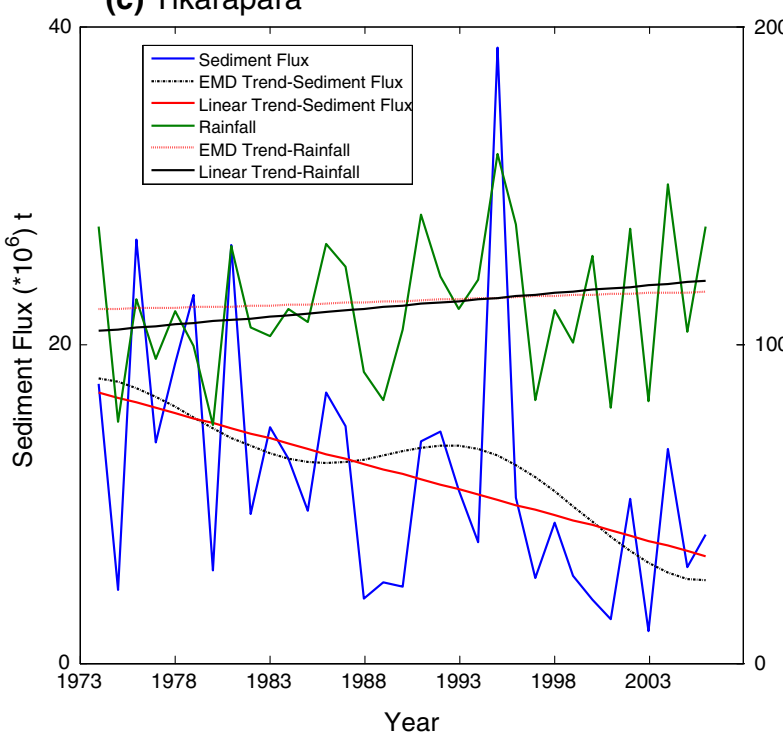

(b) Vijayawada

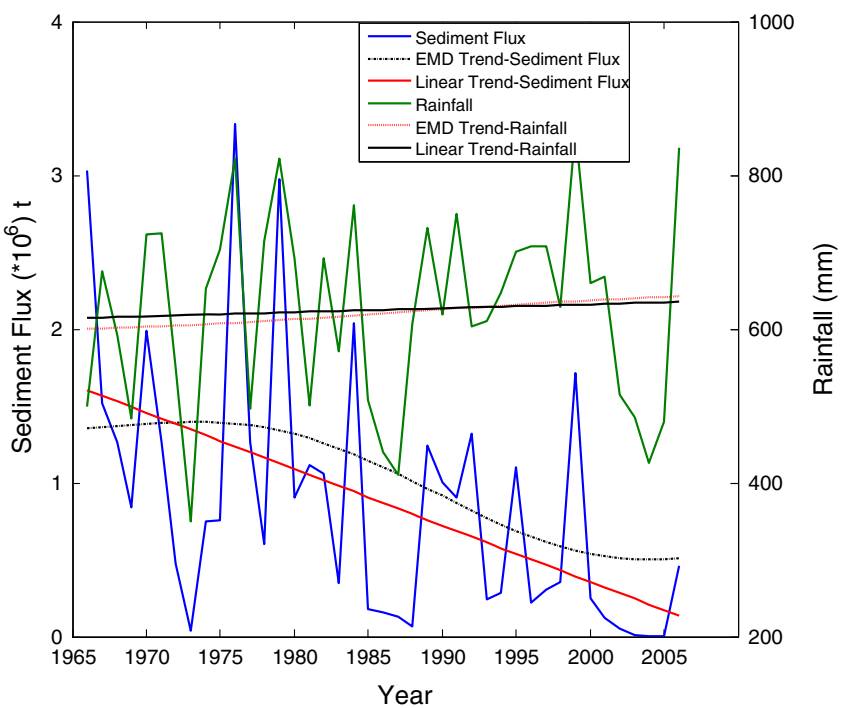

(d) Mausuri

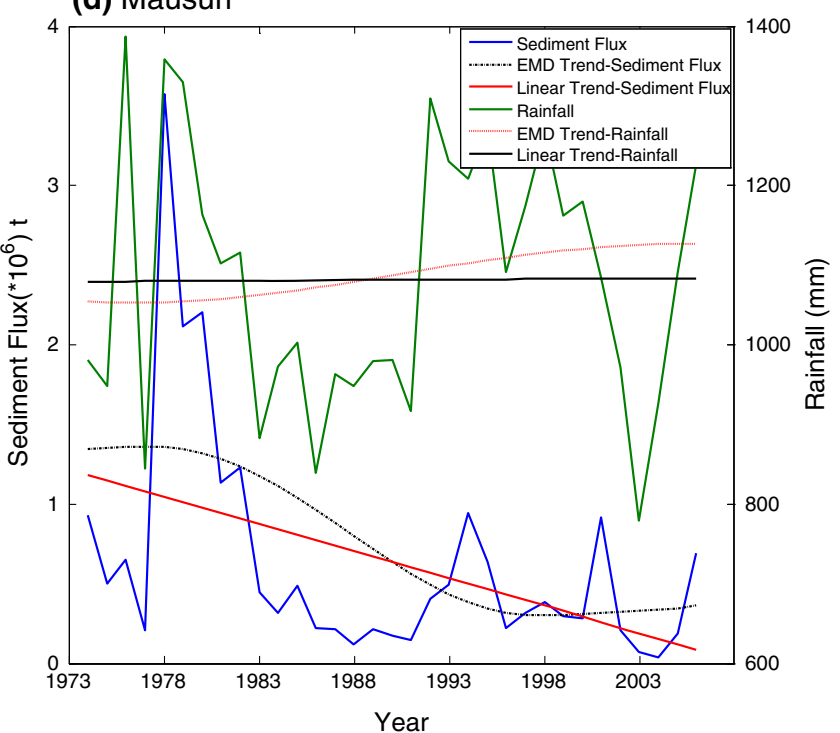

Fig. 3 Results of linear and EMD based trend analysis of sediment flux and rainfall data pertaining to seven stations

significant increase in sediment flux and a non significant decrease in rainfall trend using MK method. The plot shows sediment flux is weakly correlated with the rainfall for the station. The Pennar basin lies at a lower elevation compared to Krishna basin, which facilitates water transfer from Krishna to Pennar. The monsoon flood waters of Krishna River during South West Monsoon months can be transferred for direct use in Pennar basin without the need for water storage. The Pennar basin suffered from a prolonged drought in the 1990s and more water was required to meet the irrigation, drinking water and industrial water needs. These needs are met by water from Krishna which resulted in increase of sediment flux despite the reduction in rainfall. There are only eight dams in river Krishna which has an overall low storage capacity which also show that anthropogenic effect may not be prominent.

The linear trend plotted for Garudeshwar shows an increasing trend for rainfall whereas decreasing trend for sediment flux. Similar trend is depicted by the EMD based results of annual sediment flux and annual rainfall data. From Table 2 we can observe a significant decrease in sediment flux and a non-significant increase in rainfall trend using MK method. During the selected time period the sediment flux exhibits a decreasing trend even when rainfall is increasing which indicates that there are effects of anthropogenic interventions. 182 dams was constructed during the given time period at Narmada basin this can result in decrease of sediment flux. Over the study period, 
(e) Chennur

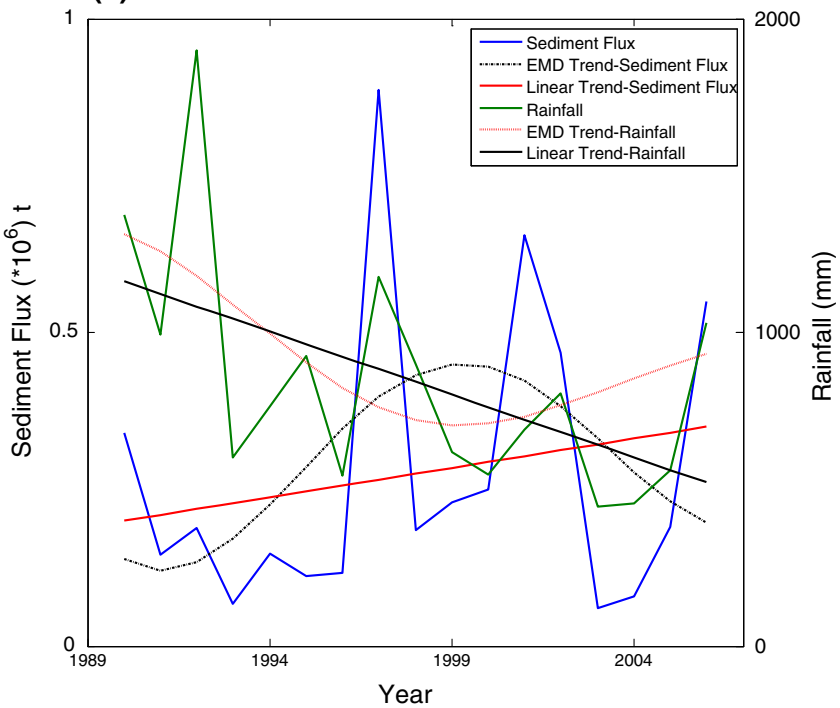

(g) Sarangkeda

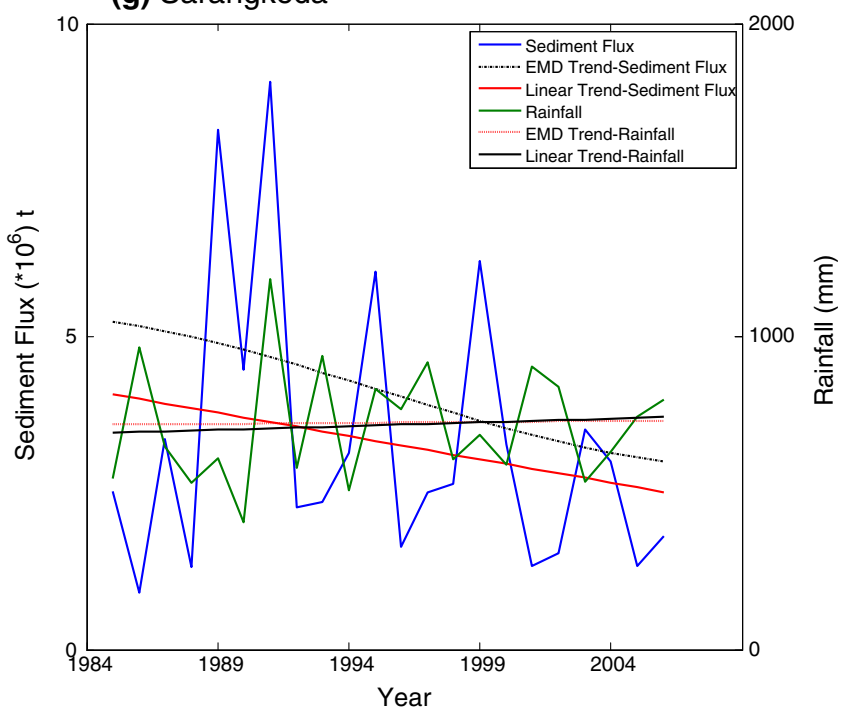

Fig. 3 continued

the sediment supply dropped significantly. This trend can be attributed to the construction of the Sardar Sarovar dam. The observed trend suggests that the anthropogenic regulation might have altered the natural fluvial system of the basin. From Table 2 we can observe non-significant increase in sediment flux and rainfall of Tapi basin. The rainfall is the primary controller of the sediment flux to the adjacent ocean in the Tapi river basin. Linear trend of sediment flux from Sarangkheda shows an increasing trend and that of rainfall data also shows an increasing trend. EMD Shows a similar trends for annual sediment flux and annual rainfall data.

The observed changes in sediment flux of the tropical rivers reflect the impacts of rainfall variability and its interaction with the anthropogenic activities. Results of trend analysis study

\section{(f) Gurudeshwar}

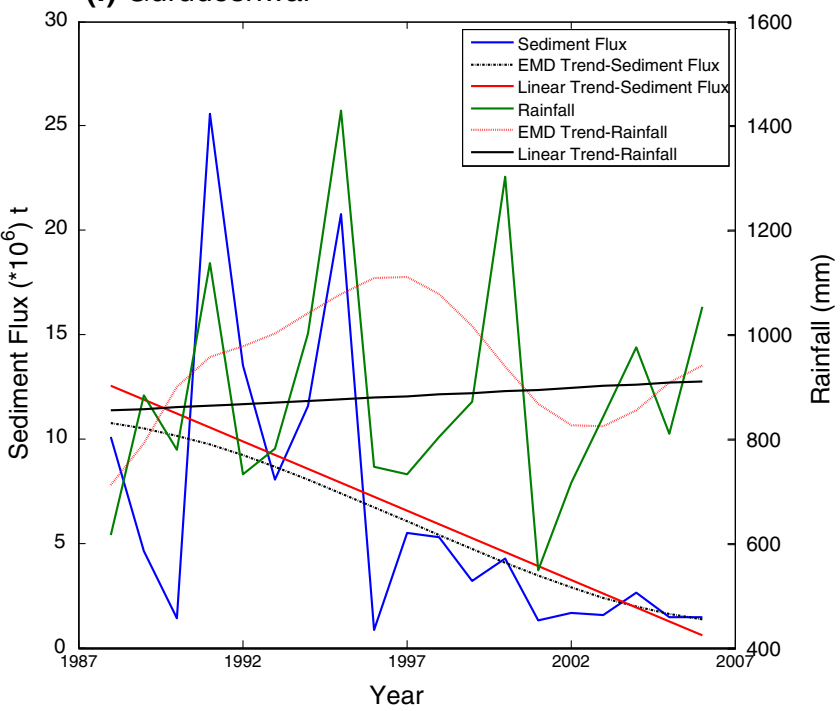

showed reduction in sediment flux in five out of seven tropical river basins in India despite the increase in rainfall throughout the study period. A decrease in sediment flux is noticed in most of the basin outlets owing to the anthropogenic effects in the form of storage structures. An increase in sediment flux is noticed in Chennur station with a decreasing trend in rainfall. This can be attributed to the flow diversion from the upstream basins to meet the water requirement of Pennar basin, which is a clear anthropogenic intervention. On contrary, a small change in rainfall towards deficit side leads to significant reduction in sediment flux as a result of diversion and storage of runoff. In short, the changes in the sediment flux are primarily due to anthropogenic influence. In order to cross-validate this point, CWT analysis of the monthly sediment flux from all the seven stations is performed by choosing the Morlet as mother wavelet 
(a) Polavaram

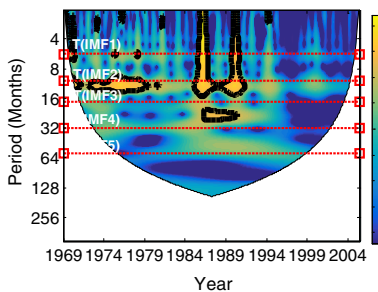

(e) Chennur

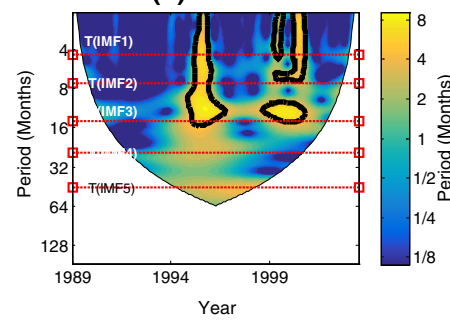

(b) Vijayawada

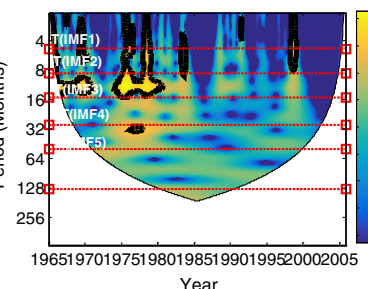

(f) Gurudeshwar

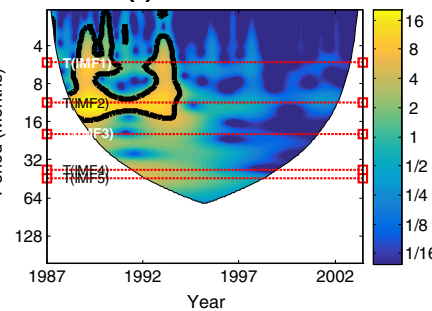

(c) Tikarapara

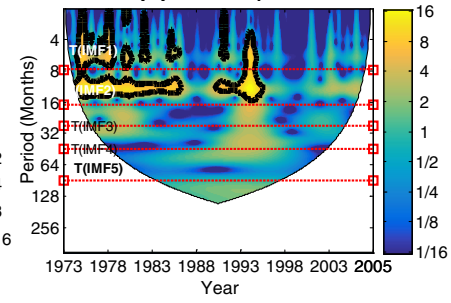

(g) Sarangkheda

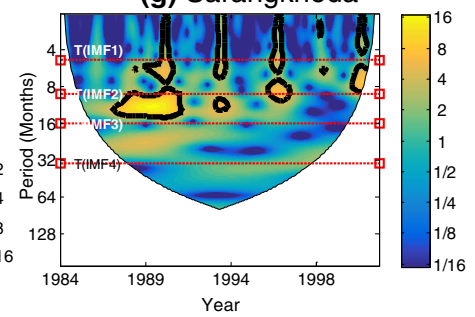

(d) Mausuri

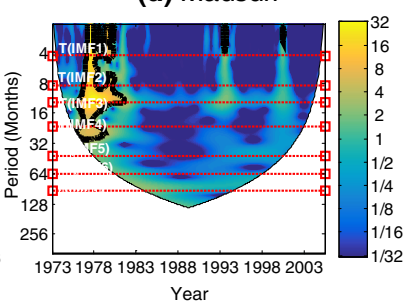

Year

Fig. 4 CWT analysis of monthly sediment flux series from seven stations. The horizontal bars indicate the mean periods of different IMFs obtained by the EMD procedure

function. The basic details of wavelet transforms are provided in Appendix 2. The results of CWT analysis are presented in Fig. 4.

Figure 4 demonstrates the pronounced annual and subannual cycles of the changes in sediment flux from different stations. From Fig. 4, it is clear that there is a no cyclic pattern of sediment flux (as the annual band is absent or discontinues) in any of the station. The monsoon rainfall being cyclic phenomena with annual periodicity, the direct influence of rainfall on sediment flux of different basin outlets can be ruled out. On the other hand, the sediment flux variability can be due to anthropogenic interventions such as construction of storage reservoirs/deforestation. Localized thick contours at intra-annual scales also infer this point and the peaks at annual band in certain years clearly decipher that occurrence of flood contributed to the sediment flux capacity of the river (for example, 1977 in Vijayawada, 1986 and 1990 in Polavaram; 1992-93 in Tikarapara). As a cross examination, the different series are also decomposed by EMD and seven IMFs for flux from Musuri station, four for flux from Sarangkheda, six for flux from Vijayawada and five for flux from the rest of the stations were resulted. The mean period of the IMFs were computed by zero crossing method (Huang et al. 2009) and the periods are superimposed upon the plots of CWT analysis. The plots show that EMD also detected the annual periodicity (red bar between 8 and 16 month period) and IMF2 is the mode representing annual cycle in all cases.

Next, a microscopic evaluation of monthly sediment flux series from all stations is performed in which, first the change points in these series were detected using the Hubert's segmentation procedure (Hubert 2000). The occurrences of floods are identified as the main cause of major 'shifts' of sediment flux in different series. Figure 5 shows the results of change point analysis of the monthly sediment flux along with the plotted data. At Polavaram station, two major peaks are observed during the years 1986 and 1990 and there had been floods during the respective years. In the plots of Tikarapara station, the repeated shifts in the 1990s are result of heavy floods experienced in Mahanadi basin. For Fig. 5 of Vijayawada station, there is a peak obtained in the graph which justifies the devastating 1977 cyclone and the resulted floods in Andhra Pradesh and its neighboring states which marooned around 100 villages and rendered lakhs of people homeless. The monsoon flood waters of Krishna river can be transferred for direct use in Pennar basin without the need for water storage in Pennar. Along with the transfer of water, some amount of sediments also get transferred which explains the peaks (sediment flow) in the sediment flux plot of Chennur station. At Garudeshwar station also, as per records, increase in water discharge was observed during the period 1980-2000. This can be attributed to influence of anthropogenic activities as no devastating flood was reported during the time period. There is no significant shift is noticed in the data from Sarangkheda station for the considered period. The trend of each segments are evaluated separately using the EMD and MK methods. A total 21 segments were identified in the six series and result of MK test for each segments are given in Table 3. It is to be noted that only the segments with at least 20 data points are considered to avoid the problem of 'end effect' while performing EMD analysis and the results of EMD analysis is presented in Fig. 6.

There are few discrepancies in the nature of trend captured by MK and EMD methods even for the segments of considerably large data length. For example, the results of 

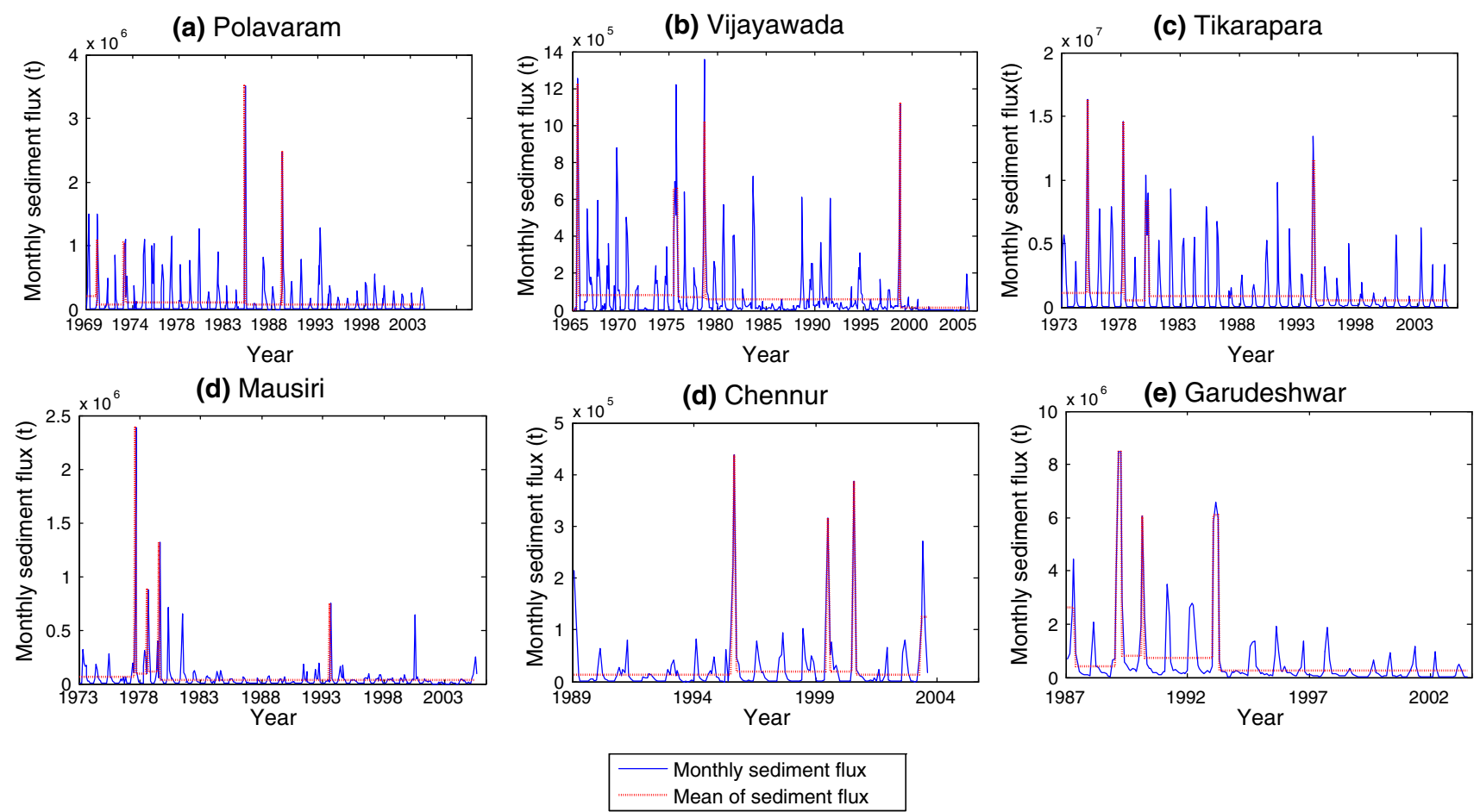

Fig. 5 Hubert's segmentation of monthly sediment flux series from different stations

Table 3 MK values of different segments of sediment flux time series from the seven stations

\begin{tabular}{|c|c|c|c|c|}
\hline Station & $\begin{array}{l}\text { Segment } \\
\text { number }\end{array}$ & Beginning & End & MK \\
\hline \multirow[t]{3}{*}{ Polavaram } & 1 & Sep-73 & Jul-86 & 1.049 \\
\hline & 2 & Sep-86 & Jul-90 & -1.275 \\
\hline & 3 & Sep-90 & Dec-05 & -2.063 \\
\hline \multirow[t]{4}{*}{ Vijayawada } & 1 & Sep-65 & Jun-75 & -2.358 \\
\hline & 2 & Dec-75 & Jul-78 & -0.276 \\
\hline & 3 & Oct-78 & Sep-98 & 0.004 \\
\hline & 4 & Nov-98 & Dec-05 & -7.038 \\
\hline \multirow[t]{5}{*}{ Tikarapara } & 1 & Jun-73 & Jul-75 & -2.248 \\
\hline & 2 & Sep-75 & Jul-78 & 0.568 \\
\hline & 3 & Sep-78 & Jun-80 & -0.677 \\
\hline & 4 & Oct- 80 & Sep-94 & 1.811 \\
\hline & 5 & Oct-94 & Dec-05 & -2.522 \\
\hline \multirow[t]{3}{*}{ Musuri } & 1 & Apr-73 & Oct-77 & -0.900 \\
\hline & 2 & Dec-79 & Oct-93 & -1.275 \\
\hline & 3 & Dec-93 & Dec-05 & -2.609 \\
\hline \multirow[t]{3}{*}{ Chennur } & 1 & Sep-89 & Jul-96 & -0.563 \\
\hline & 2 & Oct-96 & Jun-00 & -0.812 \\
\hline & 3 & Oct-01 & Jul-05 & -1.605 \\
\hline \multirow[t]{3}{*}{ Garudeshwar } & 1 & Sep-87 & Jun-90 & -1.479 \\
\hline & 2 & Sep-91 & Jun-94 & -0.237 \\
\hline & 3 & Oct-94 & Dec-05 & -4.847 \\
\hline
\end{tabular}

EMD of the segments 1 and 2 of time series from Polavaram station show decreasing and increasing trends, while MK test resulted in increasing and decreasing trend respectively. The MK value of segment 5 of the series from Tikarapara station is -2.522 while the EMD analysis displayed a monotonically increasing trend. Such discrepancy is further examined by using the discrete wavelet transform (DWT) approach. The selection of mother wavelets and appropriate decomposition level are two major challenges in the application of DWT analysis. Many of the studies experimented with the possible candidate wavelets for the hydrological forecasting problems (Maheswaran and Khosa 2012) and most of them suggested that the similarity between original time series and mother wavelet form can be considered in selection of the wavelet type. However such recommendations are still qualitative in nature and there is no scientific reasoning in selecting an appropriate mother wavelet function (Sang et al. 2016). In this study, the segment 5 of Tikarapara station, which comprises 136 data points, is considered as experimental segment for demonstration. The experimental segment along with its linear trend is provided in Fig. 7.

The experimental segment is subjected to wavelet decomposition using two of the most recommended family of wavelets - symlet (sym) and daubechies ( $\mathrm{db}$ ) wavelets are considered. Among these two family itself, there are numerous types of wavelets with several vanishing moments 

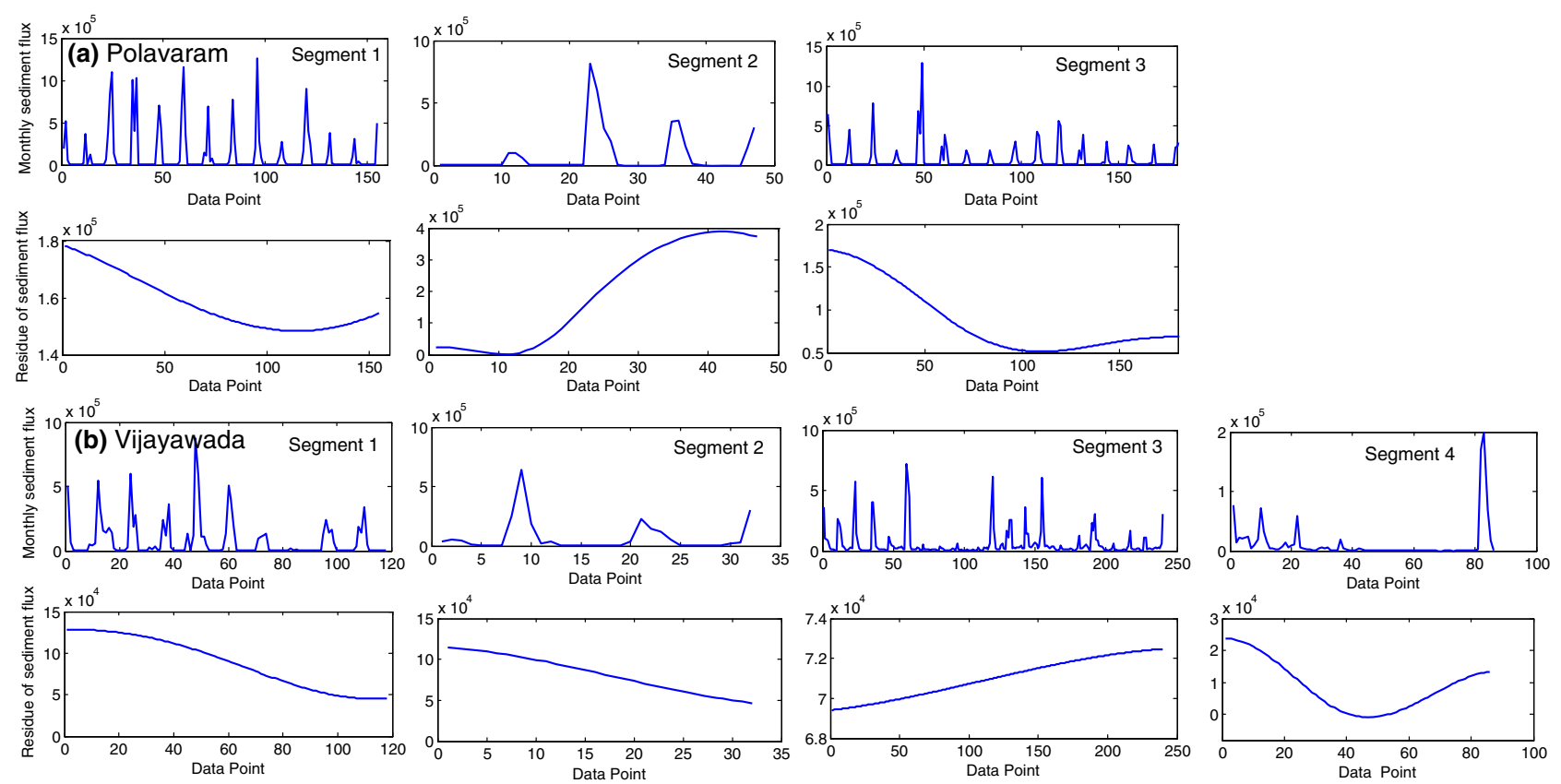

(c) Tikarapara
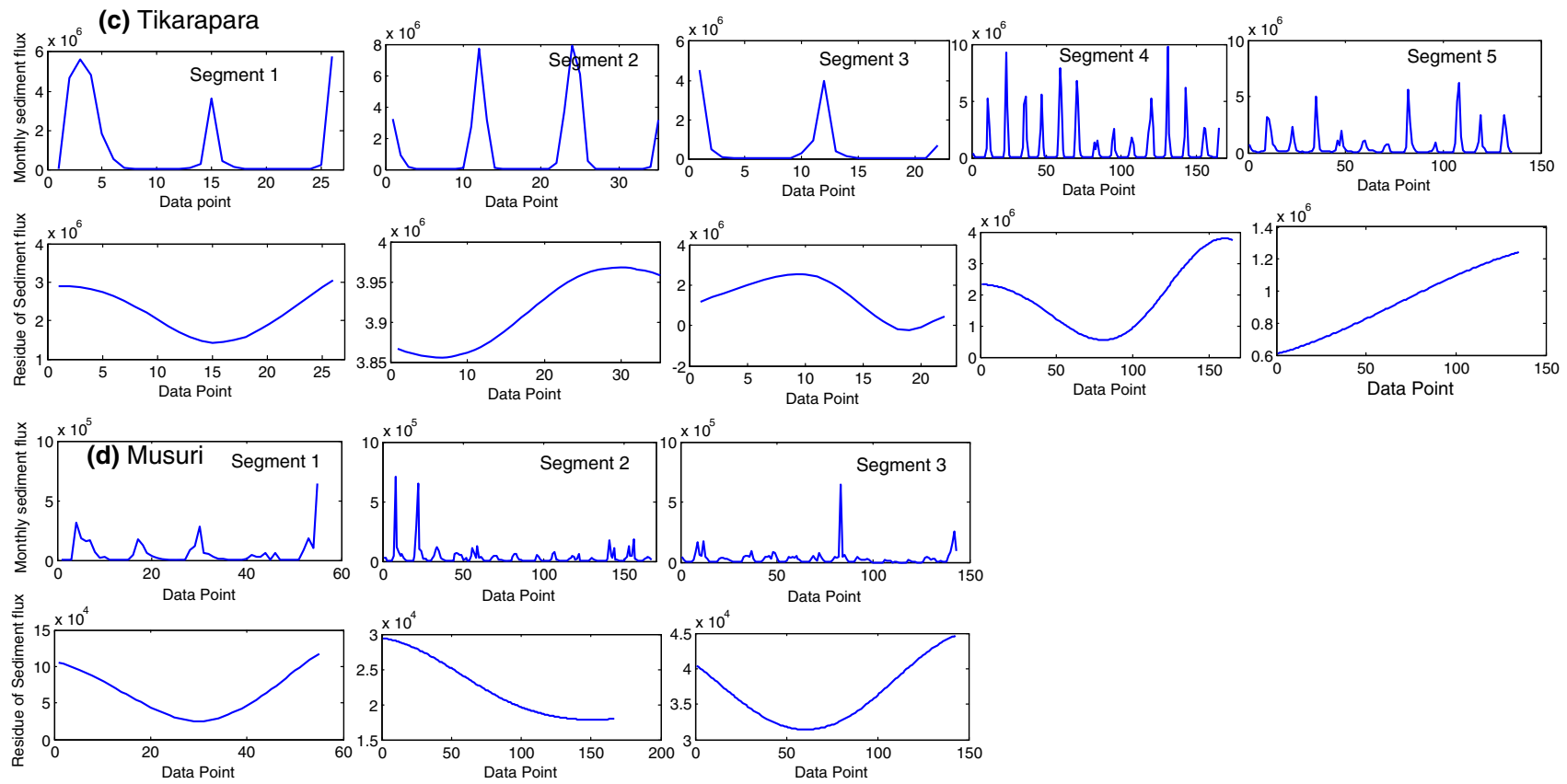

Fig. 6 EMD analysis of different segments of sediment flux series(in t) from the six observation stations

(Sang 2013). Thus we considered the type $N$ as 2 to 9 for this exercise. i.e., sym $2, \operatorname{sym} 3 \ldots$ sym $9, \mathrm{db} 2, \mathrm{db} 3 \ldots \mathrm{db} 9$ with a total of 16 cases are analysed. For each wavelet type, the decomposition level can be fixed based on the criteria proposed by de Artigas et al. (2006), who analyzed monthly geomagnetic activity indices. The decomposition levels $(L)$ is calculated using the following equation

$L=\frac{\log \left(\frac{n}{2 v-1}\right)}{\log (2)}$ where $n$ is the data length and $v$ is the number of vanishing moments.

Fixing $L$ as the decomposition level, the approximation components for each case is extracted. It is to be noted that following the above criteria, the approximation component may not be a monotonically increasing/decreasing curve for which the nature of the trend cannot be easily and directly assessed (see Nalley et al. 2012). Therefore, the methodology proposed by Nalley et al. (2012) is followed in identifying the 'true trend' and the corresponding level. 

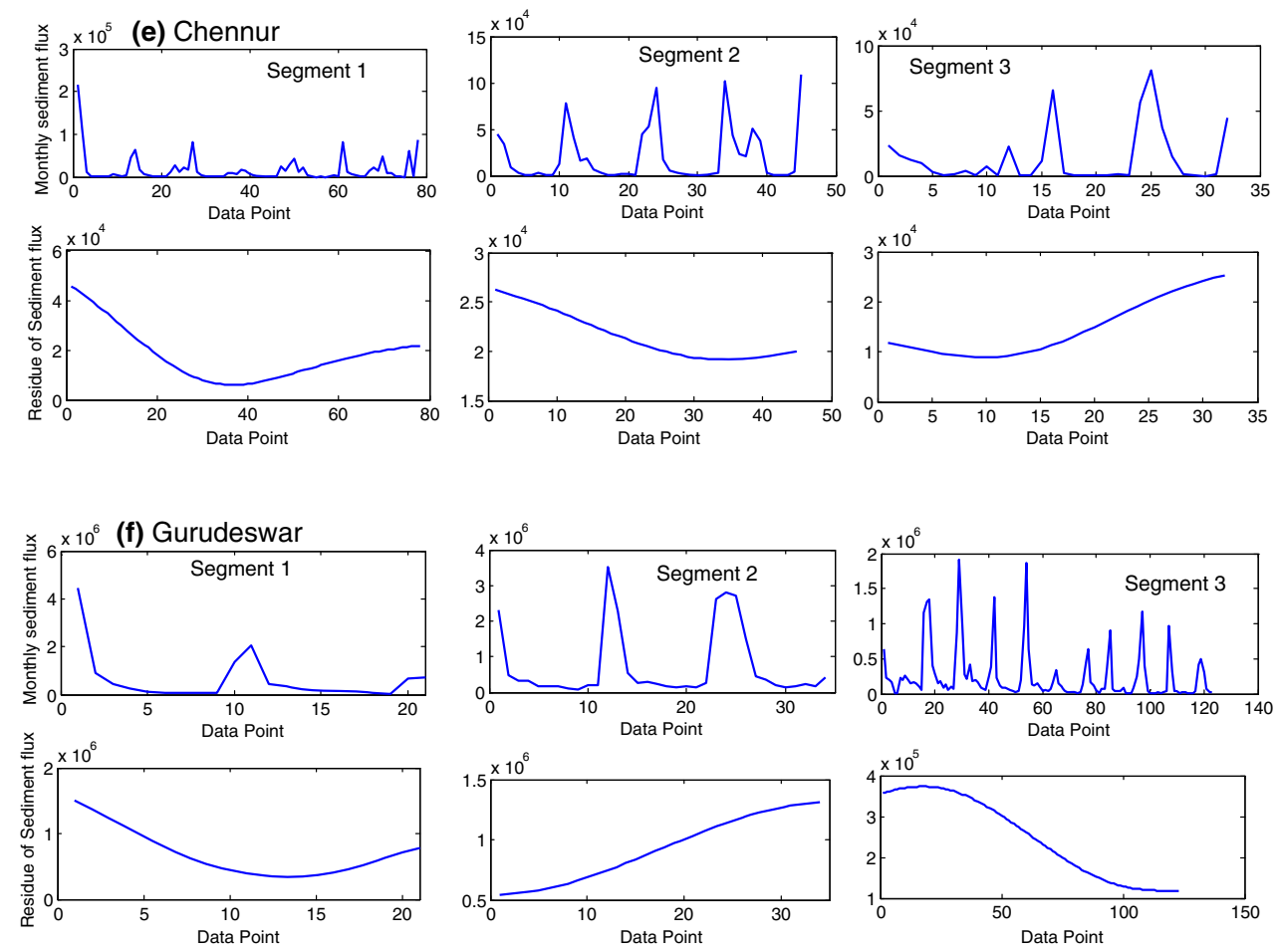

Fig. 6 continued

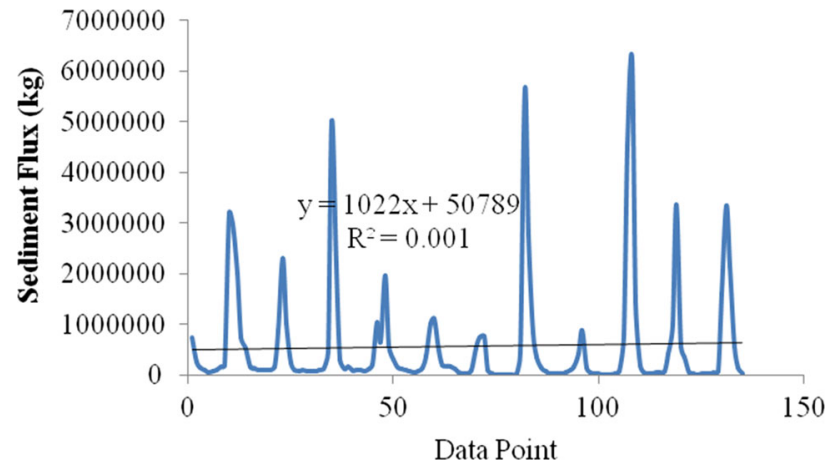

Fig. 7 Time series of experimental segment of Tikarapara station and its linear trend

According to this criteria, the MK values of both the series and the approximation component are estimated and the error statistic is computed as $e_{r}=\frac{\left|Z_{s}-Z_{a}\right|}{\left|Z_{s}\right|}$. The trend (from MK value) for which the lowest $e_{r}$ is considered as the appropriate case. The results of symlet based decomposition of the experimental segment are presented in Fig. 8. Finally the MK values of approximation component are provided in Table 4. It is noticed that the approximation of sym 7 gives lowest error statistics and corresponding to which a positive Mann-Kendall value is noticed, and it indicate an increasing trend. Similar exercise is performed using $\mathrm{db}$ family and which given $\mathrm{db} 4$ as selection approximation and inferred a positive trend. The analysis confirms that the inherent non- linear trend can be captured by the EMD method and MK fails to capture such trend of local segments as the trend estimation using the latter method is purely based on pair wise comparison of points rather than the data characteristics. The EMD method can adaptively determine the specific shape of the non-linear trend and provides a pictorial representation of the existing trend which helps in identifying the time of occurrence of change in the nature of trend. The wavelet based trend estimation procedure is chosen as a verification exercise in this study, whereas EMD operates upon the actual data, provides unique results, intuitive and simple in implementation. It doesn't demand the complex selection of basis function type and number of modes is chosen automatically based on the data characteristics. Hence EMD is a promising tool for trend analysis of hydrologic time series.

\section{Conclusions}

Results of trend analysis performed in this study showed reduction in sediment flux in five out of seven tropical river basins in India despite the increase in rainfall during the study period. A decrease in sediment flux is noticed in most of the basin outlets owing to the anthropogenic effects in the form of storage structures. An increase in sediment flux is noticed in Chennur 

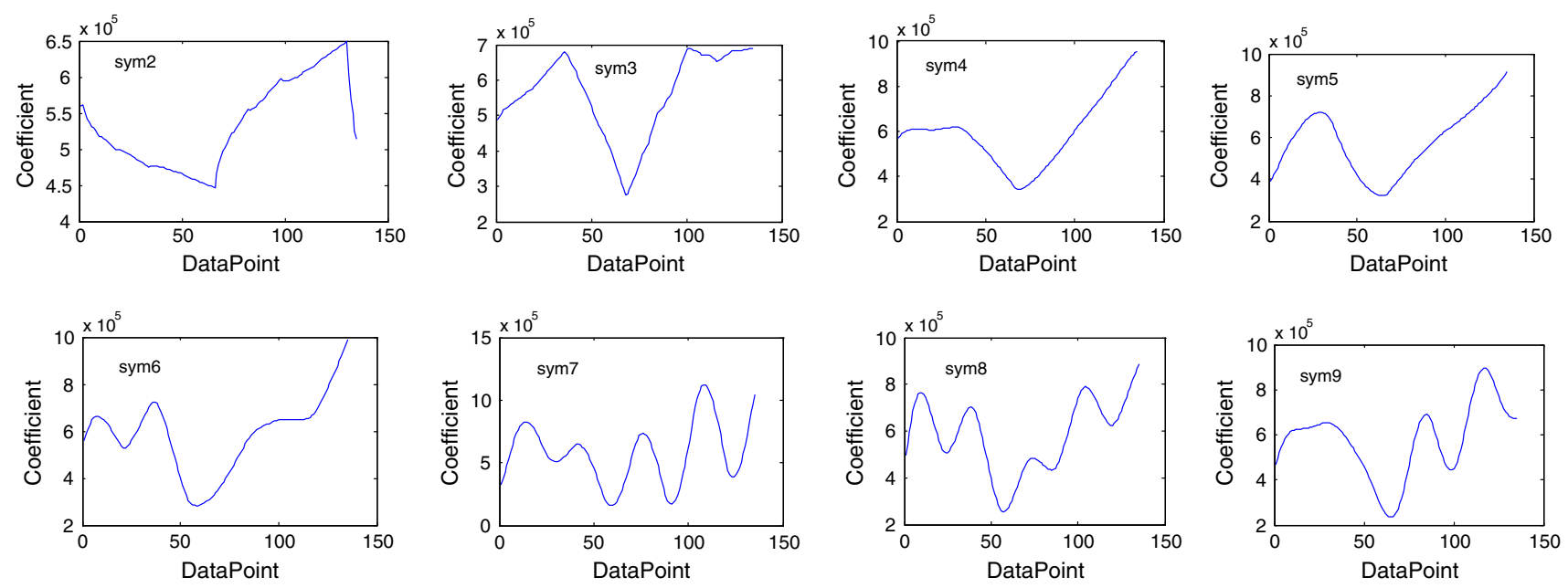

Fig. 8 Approximation components decomposition of experimental segment from Tikarapara station using of symlet wavelet

Table 4 MK values and error statistics for experimental segment of sediment flux time series from Tikarapara station

\begin{tabular}{lll}
\hline Wavelet & MMK & $e_{r}$ \\
\hline Sym2 & 3.646 & 2.446 \\
Sym3 & 2.854 & 2.131 \\
Sym4 & 1.574 & 1.624 \\
Sym5 & 7.130 & 3.827 \\
Sym6 & 3.036 & 2.204 \\
Sym7 & 0.266 & 1.105 \\
Sym8 & 3.197 & 2.267 \\
Sym9 & 1.638 & 1.649 \\
\hline
\end{tabular}

station even with a decreasing trend in rainfall. This can be attributed to the flow diversion from the upstream basins to meet the water requirement of Pennar basin, which is an anthropogenic impact. The Sequential Mann-Kendall procedure detected a potential trend turning point in sediment flux series of Tikarapara station in 1993-94; consistent reduction since 1988 in the series of Garudeshwar and erratic trends in series from Chennur and Sarangkheda stations. Further a microscopic evaluation of monthly sediment flux series from all stations is performed by first finding the change points in these series using the Hubert's segmentation procedure. The occurrences of floods are identified as the main cause of major 'shifts' of sediment flux in different series. The trends of each segments is evaluated separately using the EMD and MK methods. There are few discrepancies in the nature of trend captured by MK and EMD methods even for the segments of considerably large data length. This issue is further addressed by evaluating the trend using DWT approach. The DWT analysis showed similar trend as that obtained by EMD, which confirms that the inherent non-linear trend can be captured by the EMD method and MK fails to capture such trend of local segments.

\section{Appendix I}

\section{Sequential Mann-Kendall (SQMK) test}

SQMK test (Sneyers 1990; Gerstengarbe and Werner 1999; Modaress Modarres and Sarhadi 2009; Adarsh and Janga Reddy 2015; Kumar et al. 2016), which is progressive and retrograde analyses of the Mann-Kendall test, will produce sequential values of standardized variables with zero mean and unit standard deviation. The sequential values are calculated for the forward series $(u(t))$, and backward series $\left(u^{\prime}(t)\right)$ in the basic framework of Mann-Kendall test. The SQMK test allows for the detection of approximate beginning of a change. The procedure of SQMK test involves the following steps (Adarsh and Janga Reddy 2015)

1. The values of the original series (say) $X_{i}$ are replaced by their ranks $r_{i}$, arranged in ascending order.

2. The magnitudes of $r_{i},(i=1, \ldots, n)$ are compared with $r_{j}, \quad(j=1, \ldots i-1)$; and at each comparison, the number of cases $r_{i}>r_{j}$ are counted and denoted by $n_{i}$.

3. A statistic $t_{i}$ is defined as follows: $t_{i}=\sum n_{i}$.

4. The mean and variance of the test statistic are computed as: $E\left(t_{i}\right)=\frac{i(i-1)}{4}$ and $\operatorname{Var}\left(t_{i}\right)=\frac{i(i-1)(2 i+5)}{72}$

5. The sequential values of the statistic $u\left(t_{i}\right)$ can then be computed as:

$u\left(t_{i}\right)=\frac{\left[t_{i}-E\left(t_{i}\right)\right]}{\sqrt{\operatorname{Var}\left(t_{i}\right)}}$

where $u\left(t_{i}\right)$ is a standardized variable that has zero mean and unit standard deviation. Therefore, its sequential behavior fluctuates around zero level. In the same way, $u^{\prime \prime}\left(t_{j}\right)$ is calculated starting from the end of the series (retrograde series). If the intersection of $u(t)$ and $u^{\prime \prime}(t)$ occur within \pm 1.96 (that corresponds to the bounds at $5 \%$ 
significance level) of the standardized statistic, and it can be considered as a trend turning point where a detectable change has occurred.

\section{Appendix 2}

\section{Wavelet transforms}

Wavelet transforms are popular tools processing geophysical signals (Kumar and Georgiou 1997). There are two main types of wavelet transforms namely Continuous Wavelet Transform (CWT) and Discrete Wavelet Transform (DWT) that were being used for such applications based on the purpose of study (Sang et al. 2016). The theory of one dimensional wavelet transforms is briefly presented below:

Consider an input signal (time series), $X(t) \in(-\infty, \infty)$. The wavelet function of time $\psi(t)$ is called mother wavelet, which satisfies the following conditions (Burrus et al. 1998):

$$
\begin{aligned}
& \int_{-\infty}^{+\infty} \psi(t) \cdot d t=0, \\
& \int_{-\infty}^{+\infty}|\psi(t)|^{2} d t<\infty .
\end{aligned}
$$

The function $\psi(t)$ possesses the property set of its continuous variants $\psi_{\tau, s}(t)$ forms an orthogonal basis in a two-dimensional space and it has finite energy and fast decay.

The wavelet transform is the decomposition of $X(t)$ under different resolution levels (scales). The CWT of a discrete time series signal $X_{i}$ can be obtained from the convolution of $X_{i}(t)$ with the scaled and translated version of mother wavelet function $\psi_{o}(\eta)$

$W_{X}(\tau, s)=\sum_{i=1}^{N} X_{i}(t) \cdot \psi_{\tau, s} \times(t)$

In the above expression $\psi_{\tau, s} *(t)$ represents the complex conjugate of the normalized wavelet function $\psi_{\tau, s}(t)$

The scaling of $\psi(t)$ (compressing and expanding of the signal) can be performed using a scaling factor ' $s$ ' and translation of $\psi(t)$ (shifting the mother wavelet to the time domain of the signal) can be done using translating factor ' $\tau$ '. The scaled and translated version of the mother wavelet is given by

$\psi(t)=\psi\left(\frac{t-\tau}{s}\right)$
According the mathematical definition of CWT, the wavelet analysis investigates the resemblance of the wavelet function with the signal in hand in the sense of frequency content, i.e., if a signal has a major component of frequency corresponding to the current scale, the wavelet at the current scale will be similar to the signal at the particular location where this frequency component occurs and thus the CWT coefficient at this point in time frequency plane will be larger in magnitude. Thus a spike is observed in the contour plot of CWT. The choice of wavelet function (real or complex) is an important step in the wavelet transform. Morlet, Mexican Hat etc. are some of the mother wavelets usually employed in the CWT, out of which the Morlet is a complex function which make it possible to extract the information of both amplitude and phase, which is more suitable for analyzing the signal's oscillatory behavior (Kumar and Georgiou 1997; Torrence and Compo 1998). The Morlet wavelet function can be defined by (Morlet et al. 1982):

$\psi_{o}(\eta)=\pi^{\frac{-1}{4}} e^{i \omega_{o} \eta} e^{\frac{-\eta^{2}}{2}}$

where $\psi_{o}(\eta)$ is the wavelet function, $\eta$ is a dimensionless parameter, $i$ is the imaginary unit, $\omega_{o}$ is the dimensionless angular frequency, which provides a balance between time and frequency localization. For implementing CWT, a set of scales are to be identified 'a priori'. Here the scales are to be incremented continuously to create a complete picture of WT. These set of sclaes can be generated using fractional powers of two (Torrence and Compo 1998) $s_{j}=s_{o} 2^{j \delta j}$ where $j=0,1, \ldots ., J, \mathrm{~s}_{\mathrm{o}}$ is the smallest scale and $J$ is the maximum number of scales to be investigated. $\delta_{j}$ is the scale step size whose value depends on the mother wavelet finction. For Morelet function $\delta_{j}$ up to 0.5 can be chosen. The smallest scale is $2 \delta t$, where $\delta t$ is the time step of the measured data. The complex wavelet function results in complex wavelet coefficients constitute real and imaginary parts, i.e., amplitude $|W(\tau, s)|$ and phase given by $\tan ^{-1}\left(\frac{\operatorname{Im}(\mathrm{W}(\tau, \mathrm{s})}{\operatorname{Re}(W(\tau, s)}\right)$ For convenient description, it is common to use wavelet power spectrum $|W(\tau, s)|^{2}$ instead of continuos wavelet spectrum. The spectrum also normalized by its variance to enable the comparison among different wavelet spectra.

The calculation of wavelet coefficient at every possible scale generates a lot of data (which may sometime redundant also), which is computationally cumbersome. When the scaling factor and shifting factor of the basic wavelet function $\psi(a, \tau)$ are limited only to discrete values the operation is termed as discrete wavelet transform (DWT). The details of DWT can be explained as follows:

Let $a=a_{0}^{j} \quad$ and $\quad \tau=k a_{0}^{j} \tau_{0} \quad$ and $\quad a_{0}>0 \quad$ and $\tau_{0} \in R, \quad \forall j, k=0,1,2, \ldots, m$ 
$\psi_{j, k}(t)=a_{0}^{-j / 2} \psi\left(a_{0}^{-j} t-k \tau_{0}\right)$

Then the wavelet transform can be expressed as:

$W_{\psi} f(t)=a_{0}^{-j / 2} \int_{-\infty}^{+\infty} f(t) \psi \times\left(a_{0}^{-j} t-k \tau_{0}\right) d t$

The simplest and most efficient practice is choosing $a_{0}=2$ and $\tau_{0}=1$; scale and position are selected based on the powers of base two logarithm, called dyadic scales and positions (Mallat 1989).

$W_{\psi} f(j, k)=2^{-j / 2} \int_{-\infty}^{+\infty} f(t) \psi \times\left(2^{-j} t-k\right) d t$

In discrete time series in which $f(t)$ occurs at discrete integer times steps, the 'dyadic' DWT can be written as

$W_{\psi} f(j, k)=2^{-j / 2} \sum_{j, k \in z} f(t) \psi \times\left(2^{-j} t-k\right) d t$,

where $z$ is the domain of integer numbers.

Then the signal can be reconstructed using the following equation:

$f(t)=\sum_{j, k \in z} W_{\psi} f(j, k) \psi_{j, k}(t)$

In short, wavelet coefficients are divided into an approximation (or low frequency) coefficient $\left(A_{n}\right)$ at level $n$ through a low pass filter and detail $(D)$ (or high frequency) coefficients at different levels $1,2, \ldots, n$ through a high-pass filter. The approximation provides background information on the original signal, while $D_{1}, D_{2}, D_{3}, \ldots, D_{n}$ contains the detail information on the original signal (such as periodicity, break and jump). In a simplified form, the reconstruction stage can be expressed as:

$f(t)=A_{n}(t)+\sum_{l=1}^{n} D_{k}(t)$

where $A_{n}(t)$ is the approximation of the original signal at level $n$, and $D_{l}(t)$ are the details of the original signal at different levels $(l=1,2,3, \ldots, n$, the index for levels). $W_{\psi} f(a, \tau)$ and $W_{\psi} f(j, k)$ can reflect the characteristics of the original time series in frequency ( $a$ or $j$ ) and time domains

( $\tau$ or $k$ ). When $a$ or $j$ is small, the frequency resolution is very low, but the time domain is very high. When $a$ or $j$ become large, the frequency resolution is high, but the time domain is low. A large number mother wavelet functions such as Haar, Symlet, Daubechies, Coiflet and its resemblance with the original signal is crucial in selection of appropriate one for practical applications (Sang 2013).

\section{References}

Adarsh S, Janga Reddy M (2015) Trend analysis of rainfall in four meteorological subdivisions in southern India using non parametric methods and discrete wavelet transforms. Int $\mathrm{J}$ Climatol 35(6): 1107-1124

Agrawal A, Chak A (1991) Floods, flood plains and environmental myths. State of India's environment-a citizens report. Centre for Science and Environment, New Delhi

Biggs TW, Gaur A, Scott CA, Parthasaradhi TGR, Gumma MK, Acharya S, Turral H (2007) Closing of the Krishna basin: irrigation, streamflow depletion and macroscale hydrology. IWMI research report 111. International Water Management Institute, Sri Lanka

Bobba AG (2002) Numerical modeling of salt-water intrusion due to human activities and sea-level change in the Godavari Delta, India. Hydrol Sci J 47:67-80

Bouwer LM, Aerts JCJH, Droogers P, Dolman AJ (2006) Detecting long-term impacts from climate variability and increasing water consumption on runoff in the Krishna river basin (India). Hydrol Earth Syst Sci 10:703-713

Burrus C, Gopinath R, Guo H (1998) Introduction to wavelets and wavelet transforms. Prentice Hall, New Jersy

Chakrapani GJ (2005) Factors controlling variations in river sediment loads. Curr Sci 88:569-575

de Artigas MZ, Elias AG, de Campra PF (2006) Discrete wavelet analysis to assess long-term trends in geomagnetic activity. Phys Chem Earth 31(1-3):77-80

Dearing JA, Jones RT (2003) Coupling temporal and spatial dimensions of global sediment flux through lake and marine sediment records. Glob Planet Chang 39:147-168

Ehsanzadeh E, Ouarda TBMJ, Saley HM (2011) A simultaneous analysis of gradual and abrupt changes in Canadian low streamflows. Hydrol Process 25(5):727-739

Franske LE (2014) Warming trends: nonlinear climate change. Nat Clim Change 4:423-424

Gamage N, Smakhtin V (2009) Do river deltas in east India retreat? A case of the Krishna Delta. Geomorphol 103:533-540

Gerstengarbe FW, Werner PC (1999) Estimation of the beginning and end of recurrent events within a climate regime. Clim Res 11:97-107

Gupta H, Chakrapani GJ (2005) Temporal and spatial variations in waterflow and sediment load in Normada River Basin, India: natural and man-made factors. Geomorphol 103:533-540

Hamed KH, Rao AR (1998) A modified Mann-Kendall trend test for autocorrelated data. J Hydrol 204:182-196

Huang NE, Shen Z, Long SR, Wu MC, Shih HH, Zheng W, Yen NC, Tung CC, Liu HH (1998) The empirical mode decomposition and the Hilbert spectrum for nonlinear and non-stationary time series analysis. Proc Royal Soc Lond Ser A 454:903-995

Huang NE, Wu Z (2008) A review on Hilbert Huang Transform: Method and its applications to geophysical studies. Rev Geophys 46(2).doi: 10.1029/2007RG000228

Huang NE, Wu Z, Long SR, Arnold KC, Blank K, Liu TW (2009) On instantaneous frequency. Adv Adapt Data Anal 01:177. doi:10. 1142/S1793536909000096

Hubert P (2000) The segmentation procedure as a tool for discrete modeling of hydro-meteorological regimes. Stoch Environ Res Risk Assess 14(2000):297-304

Kale VS (2002) Fluvial geomorphology of Indian rivers, an overview. Prog Phys Geogr 26:400-433

Kendall MG (1975) Rank correlation methods. Charles Griffin, London 
Kumar M, Denis DM Surryavanshi S (2016) Long-term climatic trend analysis of Giridih district, Jharkhand (India) using statistical approach. Model Earth Syst Environ 2:116. doi:10.1007/s40808016-0162-2

Kumar P, Georgiou EF (1997) Wavelet analysis for geophysical applications. Rev Geophy 35(4):385-412

Maheswaran R, Khosa R (2012) Comparative study of different wavelets for hydrologic forecasting. Comput Geosci 46:284-295

Malini BH, Rao KN (2004) Coastal erosion and habitat loss along the Godavari delta front- a fall out of dam construction (?). Curr Sci $87: 1232-1236$

Mallat SG (1989) A theory for multi-resolution signal decomposition: the wavelet representation. IEEE Trans Pattern Anal Mach Intell 11(7):674-693

Mann HB (1945) Nonparametric tests against trend. Econometrica 13:245-259

Milliman JD, Meade RH (1983) World wide delivery of river sediment to the oceans. J Geol 101:295-303

Modarres R, Sarhadi A (2009) Rainfall trends analysis of Iran in the last half of the twentieth century. J Geophys Res 114:D03101. doi:10.1029/2008JD010707

Morlet J, Arens G, Fourgeau E, Giard D (1982) Wave propagation and sampling theory, part 1: complex signal land scattering in multilayer media. J Geophys 47:203-221

Nalley D, Adamowski J, Khalil B (2012) Using discrete wavelet transforms to analyse trends in streamflow and precipitation in Qubec and Ontario (1954-2008). J Hydrol 475:204-228

Panda DK, Kumar A, Mohanty S (2011) Recent trends in sediment load of the tropical (Peninsular) river basins of India. Glob Planet Change 75(3-4):108-118

Ranade AA, Singh N, Singh HN, Sontakke NA (2007) Characteristics of hydrological wet season over different river basins of India. Indian Institute of Tropical Meteorology (IITM) research report (RR-119)

Sang YF (2013) A review on the applications of wavelet transform in hydrology time series analysis. Atmos Res 122(2013):8-15

Sang T-F, Wang Z, Liu C (2014) Comparison of the MK test and EMD method for trend identification in hydrological time series. J Hydrol 510(2014):293-298
Sang Y, Singh V, Sun F, Chen Y, Liu Y, Yang M (2016) Waveletbased hydrological time series forecasting. J Hydrol Eng. doi:10. 1061/(ASCE)HE.1943-5584.0001347 (06016001)

Scheffe (1959) The analysis of variance. Wiley, New York

Sneyers R (1990) On the statistical analysis of series of observations. WMO technical note 143. WMO No. 415, TP-103, World Meteorological Organization, Geneva, p 192

Sonali P, Nagesh Kumar D (2013) Review of trend detection methods and their application to detect temperature change in India. J Hydrol 476(2013):212-227

Syvitski JPM (2003) Supply and flux of sediment along hydrological pathways: research for the 21st century. Glob Planet Chang 39:1-11

Syvitski JPM, Vörösmarty CJ, Kettner AJ, Green P (2005) Impact of humans on the flux of terrestrial sediment to the global coastal ocean. Science 208:376-380

Syvitski JPM, Kettner AJ, Overeem I, Hutton EWH, Hannon MT, Brakenridge GR, Day J, Vörösmarty C, Saito Y, Giosan L, Nichlls RJ (2009) Sinking deltas due to human activities. Nat Geosci 2:681-686 doi:10.1038/NGEO629

Torrence C, Compo GP (1998) A practical guide to wavelet analysis. Bull Am Meteor Soc 79(1):61-78

Unnikrishnan P, Jothiprakash V (2015) Extraction of non-linear trends using singular spectrum analysis. J Hydrol Eng. doi:10. 1061/(ASCE)HE.1943-5584.0001237 (05015007)

Walling DE, Fang D (2003) Recent trends in the suspended sediment loads of the wet season over different river basins of India. Indian Institute of Tropical world's rivers. Glob Planet Change 39:111-126

Wu Z, Huang NE, Long SR, Peng C-K (2007) On the trend, detrending, and variability of nonlinear and non-stationary time series. Proc Natl Acad Sci USA 103(38):14889-14894

Zhang Q, Chen G, Su B, Disse M, Jiang T, Xu C-Y (2008) Periodicity of sediment load and runoff in the Yangtze river basin and possible impacts of climatic changes and human activities. Hydrol Sci J 53(2):457-464 